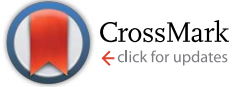

Cite this: RSC Adv., 2017, 7, 6278

Received 15th November 2016 Accepted 10th January 2017

DOI: $10.1039 / c 6 r a 26846 c$

www.rsc.org/advances

\section{Highly efficient removal of uranium(vi) from wastewater by polyacrylic acid hydrogels $\uparrow$}

\author{
Xiaofeng Yi, ${ }^{\star}$ Zhiqun Xu, Yan Liu, Xueyong Guo, Minrui Ou and Xiaoping Xu*
}

Polyacrylic acid (PAA) hydrogel prepared by radical polymerization in a clean and extremely simple way was used to adsorb $U(\mathrm{VI})$ ions from aqueous solutions. Fourier transform infrared spectroscopy (FTIR) characterization demonstrated that the PAA hydrogels were successfully synthesized, FTIR and transmission electron microscope (TEM) characterization illustrated the adsorption mechanism, and the adherence of the $U(\mathrm{VI})$ ions on PAA was confirmed by X-ray photoelectron spectroscopy (XPS) energy dispersive $X$-ray (EDX). Batch experiments with various $\mathrm{pH}$, initial concentration and contact time were conducted to evaluate the adsorption performance. The adsorption kinetics of the PAA hydrogels followed a pseudo-second-order model and exhibited a 3-stage intraparticle diffusion mode. Equilibrium data were best described by a Langmuir model, and the estimated maximum adsorption capacity for the adsorbent was $445.11 \mathrm{mg} \mathrm{g}^{-1}$. Moreover, the $\mathrm{U}(\mathrm{VI})$ loaded adsorbent could be regenerated using $0.1 \mathrm{M}$ $\mathrm{HNO}_{3}$ acid solution, and the regenerated adsorbent after five cycles could retain $90.91 \%$ of the adsorption capacity of the fresh adsorbent. The results suggested that the PAA hydrogels could be considered to be very effective and promising materials for $\mathrm{U}(\mathrm{VI})$ removal from waste water.

\section{Introduction}

Over the years, an increase in some given pollutants such as industrial waste, have contaminated fresh water and caused deterioration in the quality of potable water. Waste water from electronic device manufacture, plating facilities and the production of electricity in nuclear power plants may contain considerable amounts of toxic and polluting heavy metals., ${ }^{1,2}$ Among the metal contaminants, particular concern has been given to uranium, an important actinide element. ${ }^{3}$ Uranium is a heavy metal having both radiochemical and toxicological effects. ${ }^{4}$ Excessive amounts of uranium have entered into the environment through the activities of the nuclear industry due to different applications including nuclear power plants, the manufacture of glass, pottery glaze, electron microscopes and nuclear weapons. ${ }^{5}$ Uranium in the environment can ultimately reach the top of the food chain and be ingested by humans, causing harmful diseases such as severe kidney or liver damage. ${ }^{6}$ Therefore, methods for the removal of uranium from wastewater are of great importance.

The removal of heavy metal ions from waste water can be performed by physical and chemical methods such as adsorption, chemical precipitation, membrane filtration, chromatographic extraction, ion exchange and electrochemical techniques. $^{7,8}$ And the adsorption is considered to be

College of Chemistry, Fuzhou University, Fuzhou, 350108, China. E-mail: 927208329@qq.com; xu@fzu.edu.cn

$\dagger$ Electronic supplementary information (ESI) available: Detailed description of $\mathrm{U}(\mathrm{vI})$ sorption data fitting by kinetics models and isotherm models. See DOI: $10.1039 /$ c6ra26846c a promising and efficient method for removal of $\mathrm{U}(\mathrm{VI})$ and other metal ions. ${ }^{9}$ The adsorption mechanism involves the establishment of equilibria between the adsorbate and the adsorbent through processes such as ion exchange, chelation, complexation, electrostatic interactions and micro-precipitation even at extremely low concentrations, thus facilitates the removal of heavy metal ions from very dilute solutions. ${ }^{10}$ Adsorption of $\mathrm{U}(\mathrm{vI})$ ions on different functional groups containing adsorbents from aqueous solution had been widely studied. Results indicated that the adsorption of $\mathrm{U}(\mathrm{vI})$ ions was mostly dominated by complexation and/or ion exchange at acidic $\mathrm{pH}$ values. ${ }^{9} \mathrm{~A}$ number of absorbents such as, polymers, ${ }^{\mathbf{1 1}}$ functionalized SBA$15,{ }^{12}$ chitosan $^{13}$ and MOFs ${ }^{14}$ have been investigated for the removal of $\mathrm{U}(\mathrm{vI})$ from aqueous solutions. Among them, polymer materials, with abundant adsorption sites, have attracted wide attention. Adsorption of $\mathrm{U}(\mathrm{vI})$ cations using polymers takes place by the attraction mechanism, counting on the difference in charge between the positively charged metal ion and the negatively charged active sites distributed everywhere along the backbone and branch of any polymer, where these active sites govern the whole uptake of the $\mathrm{U}(\mathrm{vI})$ cations by the polymers.

Hydrogel, one of the most widely used polymers, consists of a three-dimensional network of hydrophilic polymers which allows the diffusion of solutes into the interior network and can be prepared using a covalent or a non-covalent approach with different functional groups such as carboxylic acid, hydroxyl and amine groups. ${ }^{15}$ These groups attached onto the polymeric networks can be used easily for the removal of metal ions. Synthesis and characterization of poly(HEA/MALA) hydrogel and 
its application in removal of heavy metal ions from water were conducted by $\mathrm{Wu}^{16}$ Wang and $\mathrm{Li}^{17}$ have used ion-imprinted composite hydrogels to investigate $\mathrm{Cu}^{2+}$ removal from waste water. $\mathrm{Pb}^{2+}$ and $\mathrm{Cu}^{2+}$ sorption properties of Gum Ghatti-grafted poly(acrylamide-co-acrylonitrile) biodegradable hydrogel were studied by Mittal. ${ }^{18}$ The most widely abundant function groups present in the structure of any hydrogel polymer are hydroxyl groups and carbonyl groups but although these hydroxyl and carbonyl groups are present in great abundance, they are not effective sites for removing and attracting the metal cations. Functional groups like carboxyl groups were found to have a very governing role in removing heavy metal cations, that they bind to the heavy metals through salt formation. ${ }^{11}$ Polyacrylic acid (PAA), is remarkably stable and can deliver high binding capacity because of its high density of carboxyl-containing. ${ }^{19}$ Although there have been extensive academic and industrial interests in the studies of the hydrogel polymer recently, ${ }^{20,21}$ few of them have focused on the removal of uranium using PAA hydrogel materials.

In the present work, PAA hydrogel was prepared by free radical polymerization as a clean and extremely simple way, and was used for removal of $\mathrm{U}(\mathrm{vI})$ ions from aqueous solution. The synthesized PAA hydrogels are not water soluble and were characterized. In order to explore the adsorption ability and mechanism of the PAA polymer hydrogel, the influence of experimental conditions such as $\mathrm{pH}$, contact time and initial concentration were investigated. The adsorption kinetics and isotherms of $\mathrm{U}(\mathrm{vI})$ cations were also evaluated. The application of PAA based hydrogel to remediate U(vI) cations as in our case has not been reported so far. From the results obtained in this work, we could establish a suitable strategy with promising application for efficient harmless removal of $\mathrm{U}(\mathrm{vI})$ ions.

\section{Materials and methods}

\subsection{Materials}

Acrylic acid (AA) and Methylene-Bis-Acrylamide (MBA) were supplied by Sinopharm Chemical Reagent Co., Ltd. Ammonium persulphate (APS) was provided by Shanghai SANGON Biological Engineering Co., Ltd, China. Sodium Hydrogen Sulfite (SHS) was purchased from Xilong Chemical Co., Ltd. All chemicals were of analytical grade and were used without further purification. All water mentioned in this paper was double deionized water (was prepared by Fuzhou University).

Stock solutions (1000 $\mathrm{mg} \mathrm{L}^{-1}$ ) of U(vI) ions were prepared by dissolving $1.859 \mathrm{~g} \mathrm{UO}_{2}\left(\mathrm{NO}_{3}\right)_{2} \cdot 6 \mathrm{H}_{2} \mathrm{O}$ in $1000 \mathrm{~mL}$ distilled water. The solutions of different concentrations used in various experiments were obtained by dilution of the stock solutions.

\subsection{Preparation of PAA hydrogel}

PAA was prepared by radical polymerization with APS as an initiator and SHS as coagulant aid in room temperature. ${ }^{22}$ The acrylic monomer with a mass fraction of $30 \%$ and $0.5 \mathrm{~g}$ MBA were dissolved in a beaker by supersonic wave. About $0.21 \mathrm{~g}$ APS and $0.21 \mathrm{~g}$ SHS were added into this solution. Then the final solution volume was diluted to $50 \mathrm{~mL}$ under mechanical stirring. Finally, the obtained solution above stands at $25^{\circ} \mathrm{C}$ for $2 \mathrm{~h}$.
The product was washed with deionized water until the unreacted substance and fluid wax were completely removed, the hydrogel was dried in vacuum freeze-drying machine for $24 \mathrm{~h}$ and stored in vacuum drying oven at $50{ }^{\circ} \mathrm{C}$.

\subsection{Characterization of adsorbent}

2.3.1 Fourier transform infrared spectroscopy (FTIR). FTIR spectra of the AA, PAA and PAA after adsorption were obtained by using a FTIR spectrophotometer. The FTIR spectrum was recorded with a spectrometer in the range of $4000-400 \mathrm{~cm}^{-1}$ using an attenuated total reflectance technique.

2.3.2 X-ray photoelectron spectroscopy, Transmission electron microscopy and energy dispersive X-ray. The elemental compositions and surface species of the PAA before and after adsorption were analyzed by XPS (ESCALAB 250). Transmission electron microscopy (TEM) images were performed on a JEOL1230 electron microscope operated at $100 \mathrm{kV}$. A scanning electron microscope (SEM, Nova Nano 230) was employed to perform EDX measurements. EDX measurements were obtained between 0 and $20 \mathrm{keV}$.

\subsection{Batch adsorption experiments}

The stock solution was diluted to give standard solutions of appropriate concentrations. The batch adsorption experiments were conducted in $50 \mathrm{~mL}$ conical flask with $10 \mathrm{~mL}$ of standard solutions. About $10 \mathrm{mg}$ PAA was then added into this solution and was left shaking for a certain period of time. The conical flask were covered with rubber plug. After filtration, the concentration of $\mathrm{U}(\mathrm{vI})$ ions in the filtrate was analyzed at a wavelength of $650 \mathrm{~nm}$ using Arsenazo-III as the complexing agent by UV-vis spectrophotometer. ${ }^{23}$

The adsorption capacity of $\mathrm{U}(\mathrm{vI})$ in the adsorption system, $q_{\mathrm{e}}$, was calculated using the following equation:

$$
\text { Adsorption capacity }\left(q_{\mathrm{e}}\right)=\left(\frac{C_{0}-C_{\mathrm{e}}}{m}\right) V
$$

where $q_{\mathrm{e}}$ is the equilibrium adsorption capacity per gram dry weight of the adsorbent $\left(\mathrm{mg} \mathrm{g}^{-1}\right), C_{0}$ and $C_{\mathrm{e}}$ are the initial and equilibrium concentration of $\mathrm{U}(\mathrm{vI})$ ions $\left(\mathrm{mg} \mathrm{L}^{-1}\right)$, respectively. $V$ is the volume of $\mathrm{U}(\mathrm{vI})$ ions solution $(\mathrm{mL})$ and $m$ is the mass of the adsorbent used $(\mathrm{g})$.

2.4.1 Effect of $\mathbf{p H}$. The effect of $\mathrm{pH}$ on the adsorption of $\mathrm{U}(\mathrm{vI})$ ions was studied at $25^{\circ} \mathrm{C}$ in a pH range of 1-5.5 at metal ion concentrations of 60,100 and $200 \mathrm{mg} \mathrm{L}^{-1}$. The solution $\mathrm{pH}$ was adjusted to the desired value by adding either nitric acid or sodium hydroxide standardized solutions.

2.4.2 Effect of the initial concentration of the $U(v)$ ions. The effect of initial concentration of the U(VI) ions was carried out by soaking $10 \mathrm{mg}$ of PAA in a series of conical flasks which contained $10 \mathrm{~mL}$ of $\mathrm{U}(\mathrm{vI})$ ions solution at definite concentrations (20-600 $\mathrm{mg} \mathrm{L}^{-1}$ ) and $\mathrm{pH}$ 4.0. The conical flasks were conditioned on the shaker at $150 \mathrm{rpm}$ while keeping the temperature at $25{ }^{\circ} \mathrm{C}$ for about $3 \mathrm{~h}$. After adsorption, solution was filtered and the residual concentration was determined.

2.4.3 Effect of contact time. The experiments were performed at $\mathrm{pH} 4.0$ by shaking $30 \mathrm{mg}$ PAA with $30 \mathrm{~mL}$ (60, 100 and 
$\left.200 \mathrm{mg} \mathrm{L}^{-1}\right) \mathrm{U}(\mathrm{vI})$ ions solution. The contents of the conical flask were agitated on a shaker at $150 \mathrm{rpm}$ and $25^{\circ} \mathrm{C}$. One milliliters of solution after adsorption were taken at time intervals for the analysis of residual $\mathrm{U}(\mathrm{vI})$ ions concentration in solution.

2.4.4 Adsorption kinetic and isotherms studies of PAA. Isotherms studies were performed by soaking $0.01 \mathrm{~g}$ PAA in a series of conical flasks containing $10 \mathrm{~mL}$ of $\mathrm{U}(\mathrm{vI})$ ions solution at different initial concentration $(20,50,100,200,300,400,500$ and $600 \mathrm{mg} \mathrm{L}^{-1}$ ) shaking for $3 \mathrm{~h}$ at $25{ }^{\circ} \mathrm{C}$. After adsorption, the residual concentration of $\mathrm{U}(\mathrm{vI})$ ions in the solution was determined. Sorption isotherms are plots of the equilibrium adsorption capacity $\left(q_{\mathrm{e}}\right)$ (according to eqn (1)) versus the equilibrium concentration of the residual $\mathrm{U}(\mathrm{vI})$ in the solution $\left(C_{\mathrm{e}}\right)$.

The kinetic studies were investigated by placing $0.01 \mathrm{~g}$ PAA in a series of conical flasks containing $10 \mathrm{~mL}$ of $\mathrm{U}(\mathrm{vI})$ ions solution with three different initial concentration $(60,100$ and $200 \mathrm{mg} \mathrm{L}^{-1}$ ), and the samples were shaked at $25{ }^{\circ} \mathrm{C}$ for designated time periods $(5,10,20,30,60,90,120,150,180 \mathrm{~min})$.

2.4.5 Desorption and regeneration experiments. After the adsorption experiment, the uranium loaded PAA (0.01 g) was left in contact with $10 \mathrm{~mL} 0.1 \mathrm{M} \mathrm{HCl}$ solution for $24 \mathrm{~h}$ at room temperature, and then washed with distilled water. Subsequently, it was dried in vacuum freeze-drying machine for $24 \mathrm{~h}$ before reuse. The adsorption-desorption procedure was conducted for five cycles under the same conditions. ${ }^{24}$

\section{Results and discussion}

\subsection{Characterization}

The FTIR spectra of samples, including AA, PAA and PAA after adsorption, are presented in Fig. 1. The strong absorption peaks at $1695 \mathrm{~cm}^{-1}$ are attributed to the $\mathrm{C}=\mathrm{O}$ of carboxylic group from AA, PAA and U-PAA complexes. ${ }^{25}$ In the spectrum of PAA, compared with that of $\mathrm{AA}$, the peak of $\mathrm{C}=\mathrm{C}$ at $1635 \mathrm{~cm}^{-1}$ disappears, which indicated that the successful synthesis of PAA. In the spectrum of U-PAA complexes, two characteristic absorption bands lying at 1530 and $1450 \mathrm{~cm}^{-1}$ are observed,

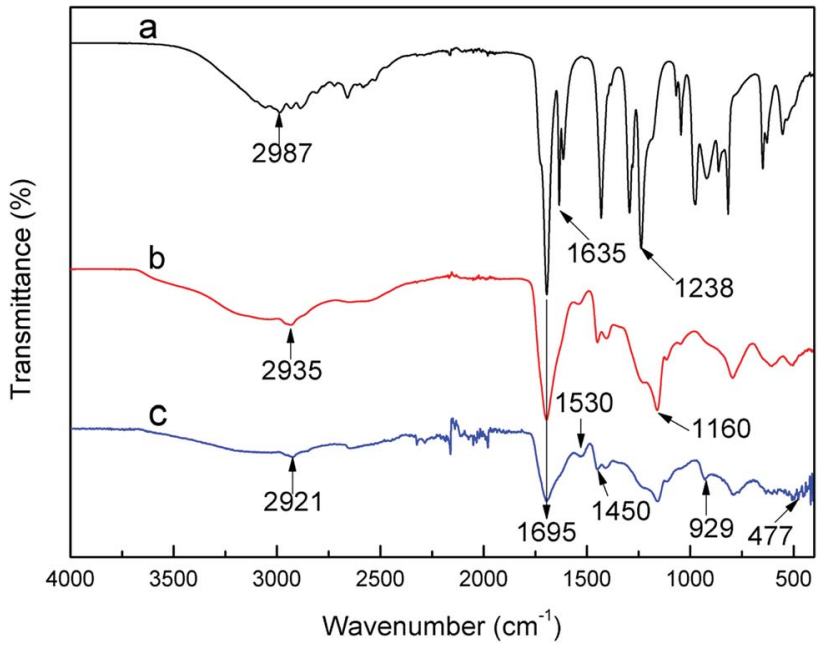

Fig. 1 Fourier transform-infrared (FT-IR) spectra of (a) AA, (b) PAA and (c) U-PAA complexes. which are attributed to the symmetric $\mathrm{COO}^{-}$and asymmetric $\mathrm{COO}^{-}$of carboxylate, respectively. And the appearance of a peak at $929 \mathrm{~cm}^{-1}$ is from the stretching vibration of $\mathrm{O}=\mathrm{U}=\mathrm{O} \cdot{ }^{26} \mathrm{In}$ addition, the weak absorption peak around $477 \mathrm{~cm}^{-1}$ can be assigned to the stretching vibration of $\mathrm{M}-\mathrm{O}$ bond. ${ }^{27}$ These data indicate that PAA hydrogels were successfully chelated with $\mathrm{UO}_{2}{ }^{2+}$ cations.

The coordination number of hexavalent uranium is often 5 or 6 in aqueous solution. ${ }^{28}$ And according to the results of $\mathrm{U}-$ PAA complexes of FTIR characterization, each $\mathrm{UO}_{2}{ }^{2+}$ is randomly combined with two carboxylates in the chain of the polymer (not necessarily in the same chain), water molecules can also participate the coordination to meet the saturated coordination.

The chemical states of the PAA before and after adsorption of uranium ions were investigated by XPS and results were shown in Fig. 2. It's obvious that PAA before adsorption showed three peaks of binding energy, C 1s (284 eV), N 1s (399 eV) and O 1s $(532 \mathrm{eV})$. However, the peak at the binding energy of $382 \mathrm{eV}$ (U 4f) appeared after adsorption of $\mathrm{U}(\mathrm{vI})$ ions. The elemental compositions of PAA calculated from the XPS spectra were summarized in Table 1. Compared with the pure PAA, the oxygen contents increased and the uranium element appeared on the PAA after adsorption, which indicated that the $\mathrm{UO}_{2}{ }^{2+}$ was successfully grafted onto PAA.

The TEM micrograph of PAA is given in Fig. 3. Before adsorption, some holes and openings in the structure were observed in Fig. 3(c), which increases the contact area and can improve metal ion adsorption. And loosely structure can be

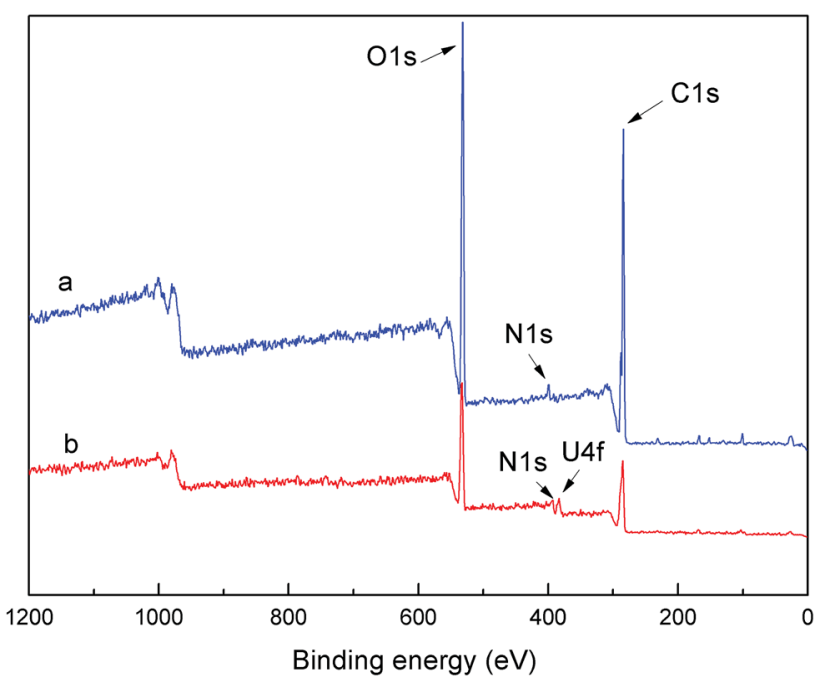

Fig. 2 XPS spectra for PAA. (a) Before adsorption and (b) after adsorption.

Table 1 Elemental composition of the PAA by XPS spectra

\begin{tabular}{lllll}
\hline Samples & C 1s (\%) & N 1s (\%) & O 1s (\%) & U 4f (\%) \\
\hline PAA before adsorption & 68.68 & 7.47 & 23.85 & 0 \\
PAA after adsorption & 48.44 & 4.24 & 45.57 & 1.72
\end{tabular}



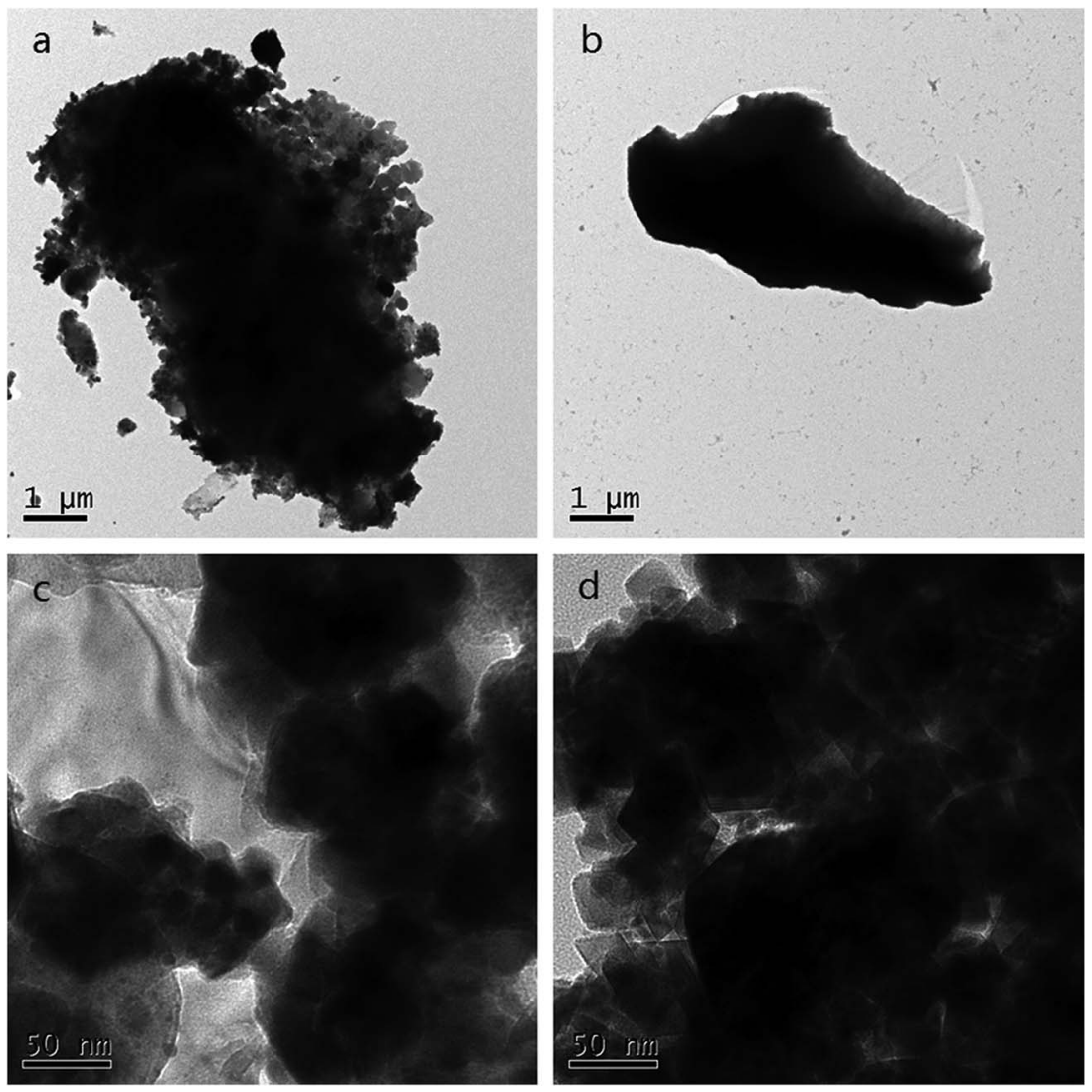

Fig. 3 TEM images of PAA. (a) and (c) Before adsorption, (b) and (d) after adsorption.

seen in Fig. 3(a), which may exist as a mass of carboxyl groups. After adsorption, Fig. 3(d) shows that the agglomeration became aggravated and dense microstructure can be seen in Fig. 3(b), demonstrating there may be strong chelation interactions between one $\mathrm{UO}_{2}{ }^{2+}$ cation and two $-\mathrm{COO}^{-}$groups. Compared Fig. 3(c) and (d), it is observed that the interstitial spaces of PAA hydrogels were filled up after the application of the adsorbent to the uranium solution. These images prove that, $\mathrm{U}(\mathrm{vI})$ ion was adsorbed by PAA hydrogel into its pores and developed a dense structure.

EDX analysis of PAA before and after adsorption were carried out to confirm the adherence of $\mathrm{U}(\mathrm{vI})$ ions onto PAA surface and depicted in Fig. 4. After adsorption, the results showed that the element $\mathrm{C}, \mathrm{O}$ and $\mathrm{N}$ decreased by $6.95 \mathrm{wt} \%, 2.76 \mathrm{wt} \%$ and 1.70 $\mathrm{wt} \%$ respectively. In addition, Fig. 4(a) shows that there are not $\mathrm{U}$ elements existed in the PAA before adsorption, while it can be noticed the appearance of U peaks in EDX spectrum in Fig. 4(b). The $\mathrm{U}$ elements accounted for $11.41 \mathrm{wt} \%$ in the PAA after adsorption, which probably ascribed to the perfect adsorption capacity of PAA. The occurrence of uranium peak in EDX spectrum confirms the $\mathrm{U}(\mathrm{vI})$ adherence onto PAA.

\subsection{Adsorption properties of PAA for the $\mathrm{UO}_{2}{ }^{2+}$ ions}

3.2.1 Effect of initial $\mathrm{pH}$ on the adsorption. The initial $\mathrm{pH}$ of the aqueous solution is an significant parameter in the adsorption process, since $\mathrm{pH}$ values affect not only the speciation of heavy metal ions in solution, but also protonation of the functional groups of the adsorbent. ${ }^{29}$ The selected $\mathrm{pH}$ values in the following experiments were set below 5.5 due to the probability of the hydrolysis and precipitation of $\mathrm{UO}_{2}{ }^{2+}$ cations at higher $\mathrm{pH}$ values. Fig. 5 illustrates the effect of $\mathrm{pH}$ on the removal efficiency of $\mathrm{UO}_{2}{ }^{2+}$ ions by PAA. As shown in the picture, it is found that the higher adsorption capacity for $\mathrm{U}(\mathrm{vI})$ ions was achieved at higher $\mathrm{pH}$ values. However, the adsorption capacity is relatively low for $\mathrm{U}(\mathrm{vI})$ ions at $\mathrm{pH}=1.0$, this may be for the reason of the leading role of the $-\mathrm{COOH}$ at low $\mathrm{pH}$, and a highly competitive adsorption between $\mathrm{H}^{+}$ions and $\mathrm{UO}_{2}{ }^{2+}$ ions in the solution. The adsorption capacity increases with the increase of the solution pH values for the PAA hydrogels when $\mathrm{pH}$ range of 1.0-4.0, which attributed to the transformation from some $-\mathrm{COOH}$ groups to $-\mathrm{COO}^{-}$groups, leading the electrostatic attraction between PAA hydrogels and $\mathrm{UO}_{2}{ }^{2+}$ cations to strengthen, and accordingly, the adsorption capacity increases. Moreover, the PAA adsorbent can adsorb $\mathrm{UO}_{2}{ }^{2+}$ quite efficiently in the $\mathrm{pH}$ range of 4.0-5.5, and the results indicated that the approximately maximum adsorption capacity of 45.89, 78.14, $142.79 \mathrm{mg} \mathrm{g}^{-1}$ occurred at an initial $\mathrm{U}(\mathrm{vI})$ concentration of 60 , 100 and $200 \mathrm{mg} \mathrm{L}^{-1}$, respectively.

3.2.2 Effect of initial concentration of the $\mathrm{U}(\mathrm{v})$ ions. Fig. 6 illustrates the effect of the initial concentrations of $\mathrm{U}(\mathrm{vI})$ ions on the adsorption by PAA at $25^{\circ} \mathrm{C}$, which indicates that along with the increasing concentrations of the $\mathrm{U}(\mathrm{vI})$ ions, the adsorption capacities of PAA enhanced sharply at first, and 

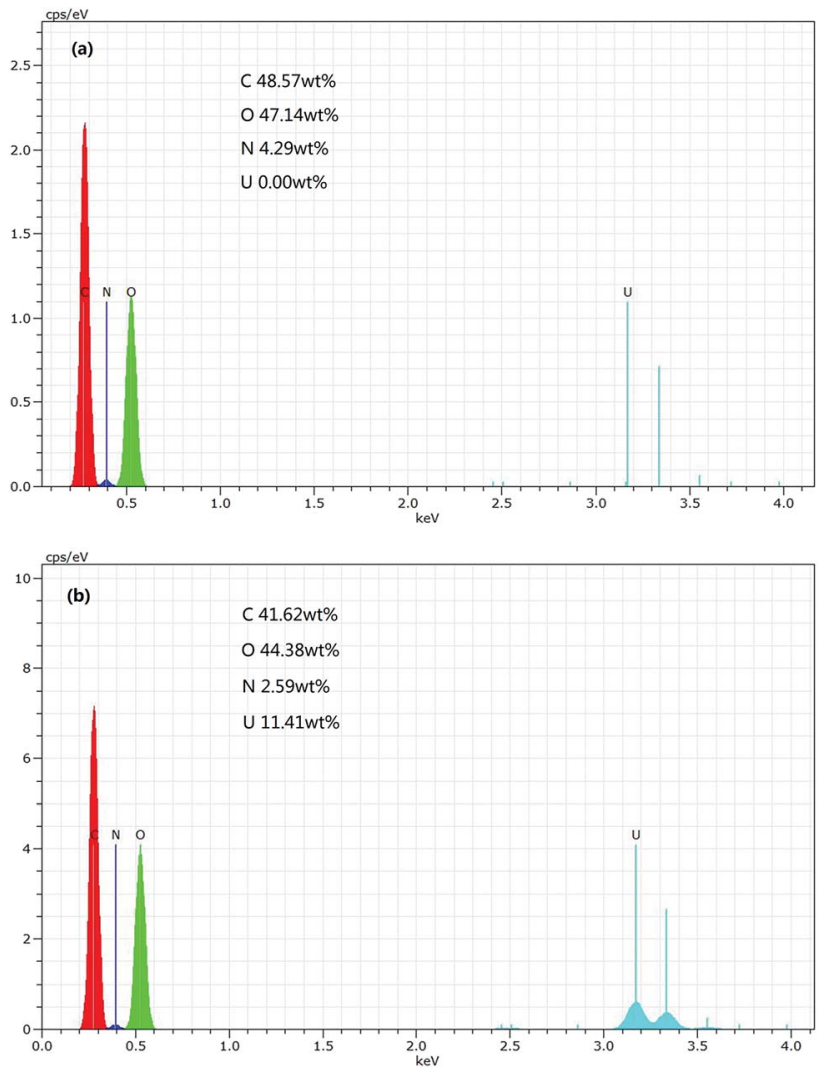

Fig. 4 EDX spectra of PAA. (a) Before adsorption (b) after adsorption.

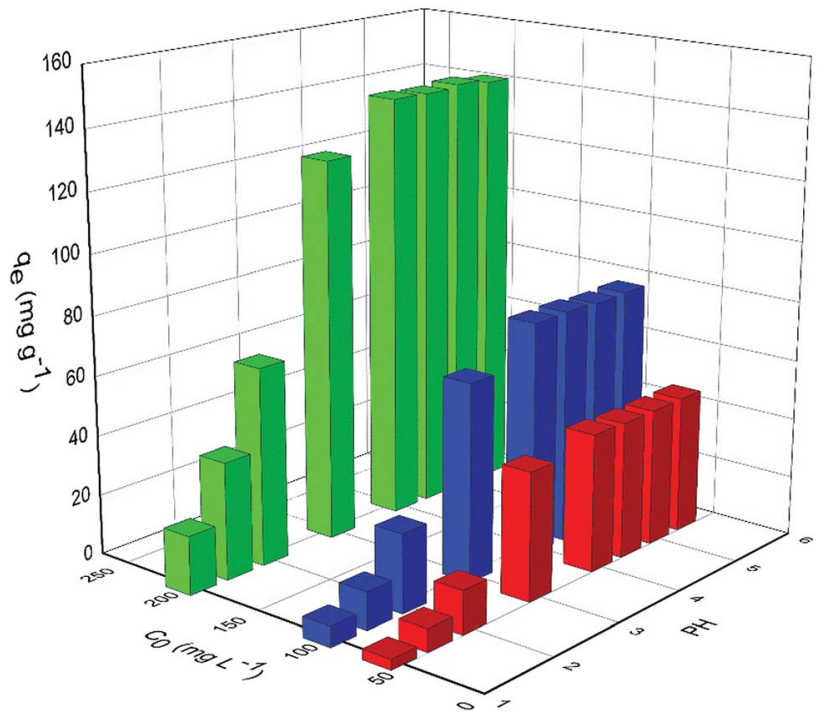

Fig. 5 The effect of initial solution $\mathrm{pH}$ on $\mathrm{U}(\mathrm{VI})$ removal by PAA hydrogels at various initial concentrations $\left(60,100\right.$ and $\left.200 \mathrm{mg} \mathrm{L}^{-1}\right)$. (Volume, $10 \mathrm{~mL}$; adsorbent dose, $0.01 \mathrm{~g} ; \mathrm{pH}$ value, 1, 1.5, 2, 3, 4, 4.5, 5, 5.5; contact time, $180 \mathrm{~min}$; temperature, $25^{\circ} \mathrm{C}$; rotating speed, 150 rpm). Note: data are presented as the mean \pm standard deviation of triplicate experiments.

then gently rise to reach a plateau, which means PAA could be completely saturated with $\mathrm{UO}_{2}{ }^{2+}$ at enough high initial concentrations.

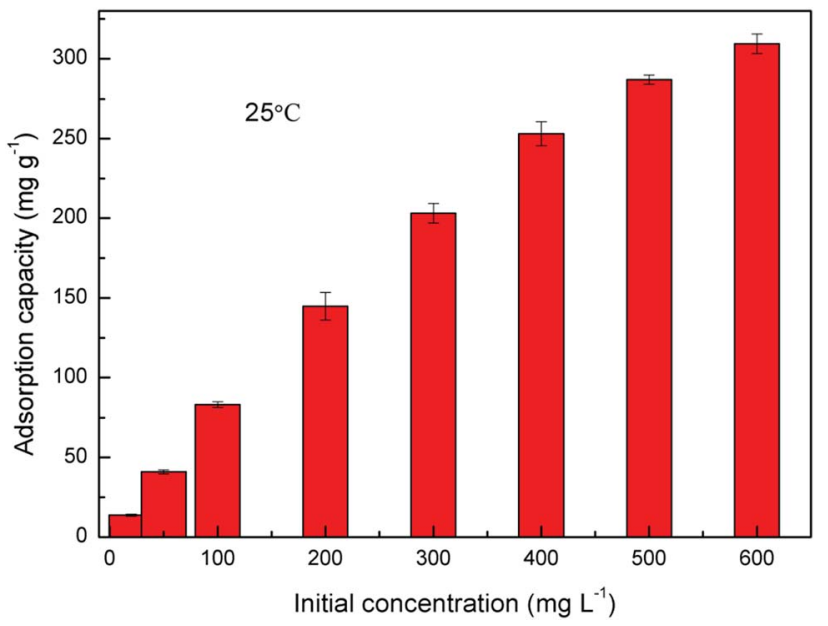

Fig. 6 The effect of initial concentrations $(20,50,100,200,300,400$, $500,600 \mathrm{mg} \mathrm{L}^{-1}$ ) on $\mathrm{U}(\mathrm{VI})$ removal by PAA hydrogels. (Volume, $10 \mathrm{~mL}$; absorbent dose, $0.01 \mathrm{~g} ; \mathrm{pH}$ value, 4.0; contact time, $180 \mathrm{~min}$; temperature, $25^{\circ} \mathrm{C}$; rotating speed, $150 \mathrm{rpm}$.)

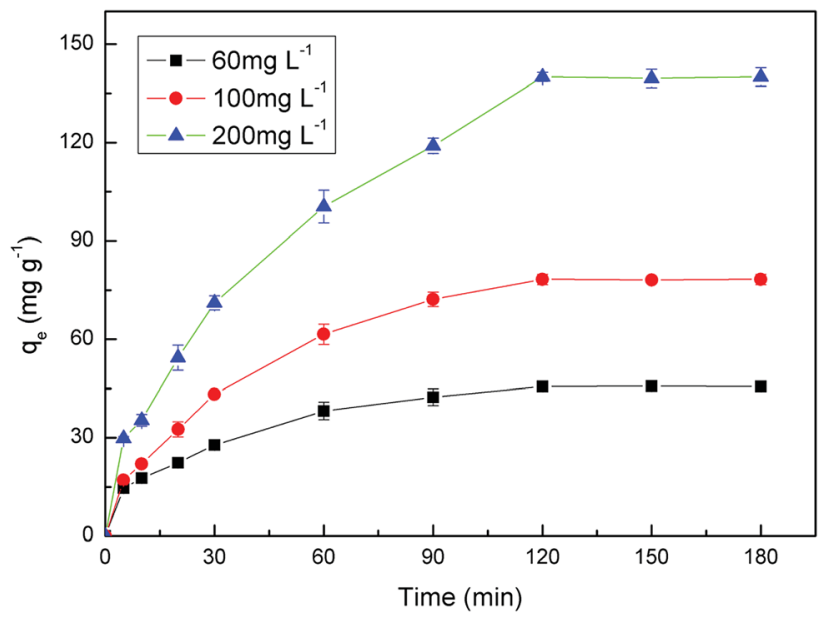

Fig. 7 Effect of contact time on $U(\mathrm{vl})$ adsorption. (Volume, $30 \mathrm{~mL}$; absorbent dose, $0.03 \mathrm{~g}$; initial concentration, 60, 100 and $200 \mathrm{mg} \mathrm{L}^{-1}$; $\mathrm{pH}$ value, 4.0; contact time, 0, 5, 10, 20, 30, 60, 90, 120, 150, $180 \mathrm{~min}$; temperature, $25^{\circ} \mathrm{C}$; rotating speed, $150 \mathrm{rpm}$.)

3.2.3 Effect of contact time on the adsorption and kinetic studies. U(vI) removal by adsorbent as a function of contact time with different initial concentration $\left(60,100\right.$ and $\left.200 \mathrm{mg} \mathrm{L}^{-1}\right)$ is shown in Fig. 7. It can be seen clearly from the figure that adsorption was rapid originally, and slowed down thereafter, and finally reached equilibrium. The initial U(vI) adsorption was a rapid process and almost reached maximum uptake at $120 \mathrm{~min}$ and no more significant uptake of U(vI) was observed at longer time. Therefore, the contact time of $120 \mathrm{~min}$ is sufficient to reach equilibrium for PAA hydrogels in the adsorption of $\mathrm{UO}_{2}{ }^{2+}$ ions, which was selected in the further experiments.

Sorption kinetics were investigated to evaluate both the rate of $\mathrm{U}(\mathrm{vI})$ sorption and the equilibrium time required for the sorption isotherm. Three adsorption kinetic models, 
Table 2 Pseudo-first-order, pseudo-second-order and intra-particle diffusion kinetic model parameters

\begin{tabular}{|c|c|c|c|c|}
\hline \multirow[b]{2}{*}{ Kinetic models } & \multirow[b]{2}{*}{ Parameters } & \multicolumn{3}{|l|}{$298 \mathrm{~K}$} \\
\hline & & $60 \mathrm{mg} \mathrm{L}^{-1}$ & $100 \mathrm{mg} \mathrm{L}^{-1}$ & $200 \mathrm{mg} \mathrm{L^{-1 }}$ \\
\hline \multirow[t]{2}{*}{ Pseudo-first-order model } & $k_{1} \times 10^{-2}$ & 2.646 & 2.602 & 1.997 \\
\hline & $R^{2}$ & 0.991 & 0.981 & 0.982 \\
\hline \multirow[t]{3}{*}{ Pseudo-second-order } & $q_{\mathrm{e}}\left(\mathrm{mg} \mathrm{g}^{-1}\right)$ & 46.8165 & 79.3651 & 143.6782 \\
\hline & $k_{2} \times 10^{-3}\left(\mathrm{~g} \mathrm{mg}^{-1} \min ^{-1}\right)$ & 1.165 & 0.4851 & 0.2245 \\
\hline & $R^{2}$ & 0.995 & 0.992 & 0.987 \\
\hline \multirow[t]{3}{*}{ Intra-particle diffusion } & $k_{1}$ & 4.0989 & 8.0955 & 13.0555 \\
\hline & $k_{2}$ & 2.3225 & 6.4599 & 12.377 \\
\hline & $k_{3} \times 10^{-3}$ & 2.08 & -2.13 & -6.35 \\
\hline
\end{tabular}
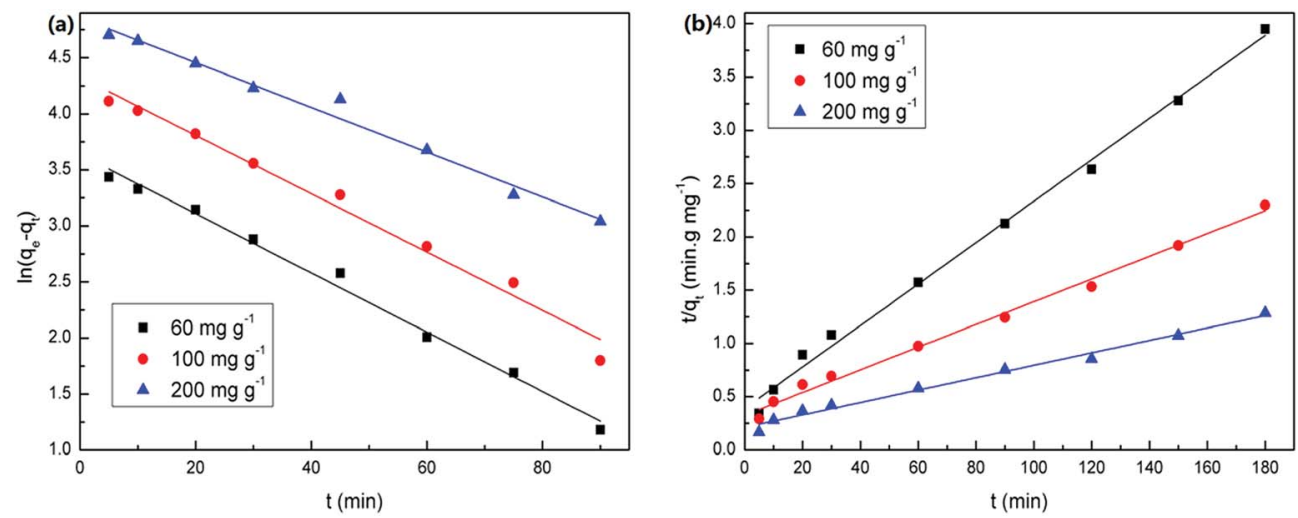

Fig. 8 Sorption kinetic plots of U(VI) ions onto PAA at various initial concentrations. (a) Pseudo-first-order and (b) pseudo-second-order sorption kinetics.

namely pseudo-first-order, pseudo-second-order and intra particle model have been chosen to describe the kinetic data. The pseudo-first-order model is expressed in the following equation: ${ }^{24}$

$$
\ln \left(q_{\mathrm{e}}-q_{t}\right)=\ln q_{\mathrm{e}}-k_{1} t
$$

The pseudo-second-order model is described in the following equation: ${ }^{30}$

$$
\frac{t}{q_{t}}=\frac{1}{k_{2} q_{\mathrm{e}}{ }^{2}}+\frac{t}{q_{\mathrm{e}}}
$$

where $q_{t}$ and $q_{\mathrm{e}}\left(\mathrm{mg} \mathrm{g}^{-1}\right)$ stand for the amount of $\mathrm{U}(\mathrm{vI})$ ions adsorbed on the adsorbents at time $t$ (min) and equilibrium, respectively. $k_{1}\left(\mathrm{~min}^{-1}\right)$ is the rate constant of the pseudo-firstorder model, while $k_{2}\left(\mathrm{~g} \mathrm{mg}^{-1} \mathrm{~min}^{-1}\right)$ is the pseudo-secondorder rate constant.

The values of corresponding kinetic parameters calculated from the pseudo-first and the pseudo-second-order models are presented in Table 2, and the plots of kinetic model are shown in Fig. 8. The results from Fig. 8(a) and (b) indicate that the pseudo-second order model fits the experiment data better than the pseudo-first order model. Also, the theoretical calculated $q_{\text {e,cal }}$ values obtained from the pseudo-second order model are closer to the experimental ones $q_{\mathrm{e}, \exp }$ and this further confirms the best applicability of the pseudo-second-order model.
In order to investigate if pore or film diffusion was the controlling step in the adsorption, intra-particle diffusion model was further tested as follows: ${ }^{31}$

$$
q_{t}=k_{\mathrm{i}} t^{1 / 2}+C
$$

where $k_{\mathrm{i}}\left(\mathrm{mg} \mathrm{\textrm {g } ^ { - 1 }} \mathrm{min}^{-1 / 2}\right)$ is the intra-particle diffusion rate constant and $C$ is the thickness of the boundary layer and

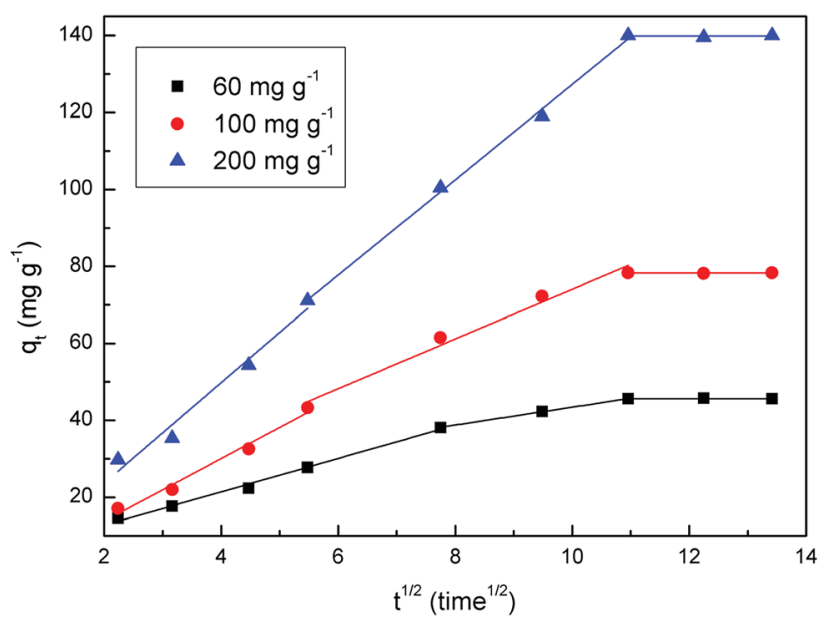

Fig. 9 Intraparticle diffusion kinetics of $U(\mathrm{VI})$ onto PAA at various initial concentrations. 
$q_{t}\left(\mathrm{mg} \mathrm{g}^{-1}\right)$ stands for the amount of metal ions adsorbed on the adsorbents at time $t$ ( $\mathrm{min})$. Fig. 9 shows the intra-particle diffusion plots for the $\mathrm{U}(\mathrm{vI})$ cations adsorption on PAA. It is apparent that more than one linear portion appear in all of the plots, which indicates that the adsorption is affected by two or more steps. ${ }^{32}$ Moreover, intra-particle diffusion rate constants in every step follow the order of $k_{1}>k_{2}>k_{3}$, which are presented in Table 1 . This could be explained as follows: the first portion represents instantaneous adsorption or external surface adsorption stage, in which large numbers of $\mathrm{U}(\mathrm{vI})$ ions were adsorbed rapidly by $\mathrm{COO}^{-}$of the PAA. After almost all the exterior $\mathrm{COO}^{-}$were occupied, the $\mathrm{U}(\mathrm{vI})$ ions started to enter into the pores of the adsorbents and the second portion of the plot seemed to refer to the diffusion into mesopores. Moreover, the third portion of the plots was nearly parallel, suggesting that equilibrium state reached at last. $^{33}$

3.2.4 Adsorption isotherm studies. Adsorption isotherm studies are remarkably significant to determine the efficacy of adsorption. Several adsorption isotherms initially used for gas phase adsorption are available and readily adopted to correlate adsorption equilibria in heavy metals adsorption. Some wellknown ones are Langmuir, Freundlich, Temkin, RedlichPaterson and Sips equation. ${ }^{34}$ In this work, the adsorption isotherms were investigated using three equilibrium models, which are Langmuir, Freundlich and Temkin isotherm models.

The Langmuir isotherm assumes that monolayer adsorption takes place on an adsorbent that have a structurally homogeneous surface, on which the binding sites have the same affinity for the adsorption, and no interaction occurs between adsorbates. ${ }^{35}$ The Langmuir model can be represented as:

$$
q_{\mathrm{e}}=\frac{q_{\mathrm{max}} K_{\mathrm{L}} C_{\mathrm{e}}}{1+K_{\mathrm{L}} C_{\mathrm{e}}}
$$

where $C_{\mathrm{e}}$ is the equilibrium concentration of the adsorbate (mg $\left.\mathrm{L}^{-1}\right), q_{\mathrm{e}}$ is adsorption capacity at equilibrium $\left(\mathrm{mg} \mathrm{g}^{-1}\right), q_{\max }$ is the maximum adsorption capacity of the adsorbent $\left(\mathrm{mg} \mathrm{g}^{-1}\right)$ and $K_{\mathrm{L}}$ is the Langmuir adsorption constant related to the energy of adsorption ( $\mathrm{L} \mathrm{mg}^{-1}$ ).

The well-known Freundlich isotherm is an empirical equation predicting that the adsorption occurs on an energetically heterogeneous surface, on which the adsorbed molecules are interactive and adsorption capacity is related to the concentration of adsorbate at equilibrium. ${ }^{36}$ The Freundlich model is expressed as:

$$
q_{\mathrm{e}}=K_{\mathrm{F}} C_{\mathrm{e}^{n}}^{\frac{1}{n}}
$$

where $K_{\mathrm{F}}$ and $n$ are the Freundlich constants related to adsorption capacity and intensity, respectively, $q_{\mathrm{e}}$ and $C_{\mathrm{e}}$ are the adsorption capacity at equilibrium $\left(\mathrm{mg} \mathrm{g}^{-1}\right)$ and equilibrium concentrations of adsorbate in liquid phases $\left(\mathrm{mg} \mathrm{L} \mathrm{L}^{-1}\right)$, respectively.

The Temkin isotherm is based on the assumption that the free energy of adsorption is a function of the surface coverage and takes into account the interactions between adsorbents and adsorbates. ${ }^{37}$ The isotherm model is written as

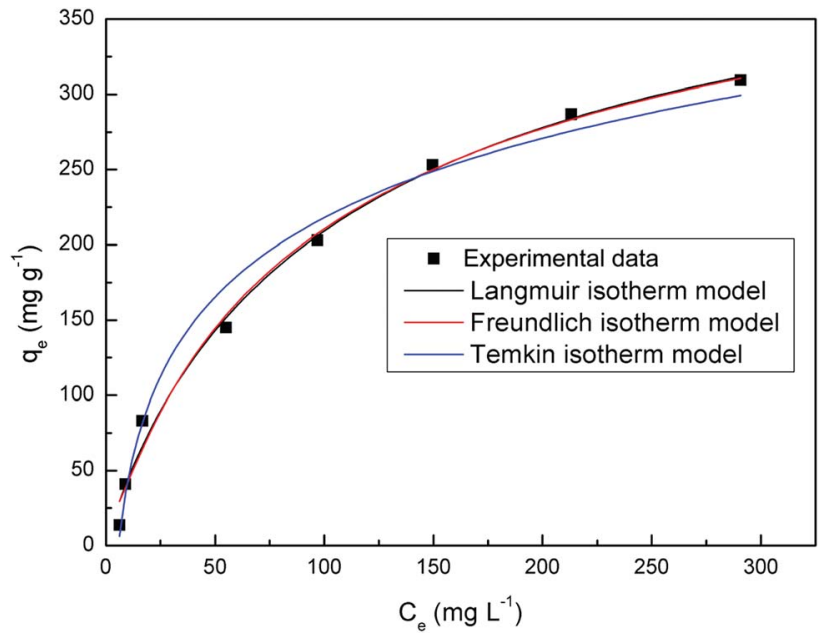

Fig. 10 Non-linear Langmuir, Freundlich and Temkin isotherm for the adsorption of $\mathrm{U}(\mathrm{vl})$ ions onto PAA hydrogels. (Volume, $10 \mathrm{~mL}$; absorbent dose, $0.01 \mathrm{~g}$; initial concentration, 20, 50, 100, 200, 300, 400, 500 and $600 \mathrm{mg} \mathrm{L}^{-1}$; $\mathrm{pH}$ value, 4.0; contact time, $180 \mathrm{~min}$; temperature, $25^{\circ} \mathrm{C}$; rotating speed, $150 \mathrm{rpm}$.)

$$
q_{\mathrm{e}}=\frac{R T}{b_{\mathrm{T}}} \ln \left(a_{\mathrm{T}} C_{\mathrm{e}}\right)
$$

where $R$ is the ideal gas constant $\left(8.314 \mathrm{~J} \mathrm{~mol}^{-1} \mathrm{~K}^{-1}\right), T$ is the absolute temperature $(\mathrm{K}), a_{\mathrm{T}}$ is the equilibrium binding constant corresponding to the maximum binding energy and $b_{\mathrm{T}}$ is the Temkin isotherm constant.

Fig. 10 shows the equilibrium adsorption of $\mathrm{UO}_{2}{ }^{2+}$ onto the PAA hydrogels and the fitting plot of the three isotherm models. For the studied system, the Langmuir isotherm correlates best $\left(R^{2}=0.991\right)$ with the experimental data from adsorption equilibrium of $\mathrm{UO}_{2}{ }^{2+}$ by PAA in these three models, suggesting a monolayer adsorption. Furthermore, the degree of suitability of adsorbent towards $\mathrm{U}(\mathrm{vI})$ ions was assessed from the values of separation factor constant $\left(R_{\mathrm{L}}\right)$, which has always been used to indicate the adsorption is favorable or not. ${ }^{38}$ The value of $R_{\mathrm{L}}$ will indicate the type of isotherm is, irreversible $\left(R_{\mathrm{L}}=0\right)$, favorable $\left(0<R_{\mathrm{L}}<1\right)$, linear $\left(R_{\mathrm{L}}=1\right)$, or unfavorable $\left(R_{\mathrm{L}}>1\right)$, which can be calculated from the following equation:

$$
R_{\mathrm{L}}=\frac{1}{1+K_{\mathrm{L}} C_{0}}
$$

where $K_{\mathrm{L}}\left(\mathrm{L} \mathrm{mg}^{-1}\right)$ is the Langmuir constant, and $C_{0}\left(\mathrm{mg} \mathrm{L}^{-1}\right)$ is the initial concentration of $\mathrm{U}(\mathrm{vI})$ ions. The $K_{\mathrm{L}}$ value obtained from fitting plot of Langmuir isotherm model is 0.0136. And the $R_{\mathrm{L}}$ values of PAA, according to eqn (5), are greater than zero and less than unity, which suggests that the adsorption processes, between the adsorbent (PAA) and $\mathrm{UO}_{2}{ }^{2+}$, are favorable. The maximum adsorption capacity of PAA for $\mathrm{UO}_{2}{ }^{2+}$ obtained by Langmuir isotherm model is $445.11 \mathrm{mg} \mathrm{g}^{-1}$.

3.2.5 Desorption and reusability studies. From practical point of view, reusability is an very significant feature of an advanced adsorbent. The adsorption behavior of U(vI) onto PAA hydrogels is remarkably reliant on $\mathrm{pH}$ and both a lower and higher $\mathrm{pH}$ values negatively impact the uranium adsorption. At high $\mathrm{pH}$, a stable precipitation product, $\mathrm{UO}_{2}(\mathrm{OH})_{2}$, can be 


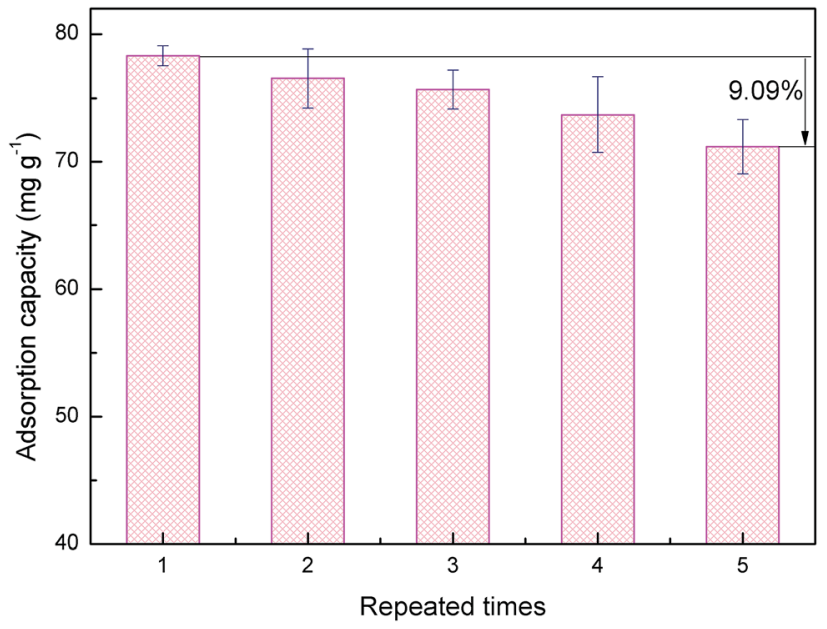

Fig. 11 Adsorption/desorption cycles (initial concentration: $100 \mathrm{mg} \mathrm{L}^{-1}$ ).

Table 3 Comparison of adsorption capacities for $U(\mathrm{vl})$ ion of various adsorbents

\begin{tabular}{lll}
\hline Adsorbent & $\begin{array}{l}\text { Adsorption } \\
\text { capacity }\left(\mathrm{mg} \mathrm{g}^{-1}\right)\end{array}$ & Reference \\
\hline $\mathrm{HNTs}^{-} \mathrm{Fe}_{3} \mathrm{O}_{4}$ & 88.32 & 40 \\
AgOH-MWCNTs & 140 & 41 \\
$\mathrm{CMPEI} / \mathrm{MSU}-\mathrm{H}$ & 124 & 42 \\
$\mathrm{SA} / \mathrm{CMC}$ & 101.76 & 43 \\
SBA-15 & 170 & 44 \\
PAA hydrogels & 445.11 & This work
\end{tabular}

formed by the desorbed uranium, ${ }^{39}$ which was difficult to separate from the adsorbent. Therefore, desorption of the adsorbed $\mathrm{U}(\mathrm{vI})$ from PAA can only take place in acid solution $\left(0.1 \mathrm{M} \mathrm{HNO}_{3}\right)$. The capacity of PAA for five adsorption-desorption cycles is shown in Fig. 11. The PAA hydrogels could be utilized repeatedly and the adsorption capacity only slightly declined (by 9.09\%). The regeneration experiments in this study indicate that the PAA hydrogels has the potential of regeneration and can be used as an efficient adsorbents for wastewater treatment.

3.2.6 Comparison with other adsorbents. Table 3 presents a comparison of the $\mathrm{U}(\mathrm{vI})$ adsorption capacity of other adsorbents including organic, inorganic materials and composites of them. Among these materials, HNTs- $\mathrm{Fe}_{3} \mathrm{O}_{4}, \mathrm{AgOH}-\mathrm{MWCNTs}$, CMPEI/ MSU-H and SA/CMC were relatively difficult to prepared due to their complex preparation process. And SBA-15 is low in chemical reactivity. Compared to these adsorbents, PAA hydrogels can be used as efficient adsorbents due to its simple synthesizing procedures and high chemical reactivity. Moreover, PAA hydrogels performed relatively excellent adsorption capacity.

\section{Conclusions}

In this work, we have demonstrated a clean and extremely simple strategy for preparing PAA hydrogels, which are identified to be an excellent adsorbent for the removal of $\mathrm{UO}_{2}{ }^{2+}$ ion from aqueous solutions. Structure characterization indicated that the PAA hydrogel was successfully synthesized, complexation took a dominant role in adsorption process and $\mathrm{U}(\mathrm{vI})$ ions were adhered onto PAA hydrogels. The adsorption kinetics of PAA hydrogels were well described by pseudosecond-order kinetic and intraparticle diffusion model. Langmuir model was most appropriate to fit the adsorption data, and the maximum sorption capacity of PAA for U(vi) was evaluated to be $445.11 \mathrm{mg} \mathrm{g}^{-1}$ at $\mathrm{pH}$ 4.0. According to this paper, its good reusability and excellent adsorption capacity give PAA hydrogels a high potential for practical application in the removal of heavy metal ions from polluted water.

\section{References}

1 W. S. W. Ngah, A. Kamari and Y. J. Koay, Equilibrium and kinetics studies of adsorption of copper(II) on chitosan and chitosan/PVA beads, Int. J. Biol. Macromol., 2004, 34, 155161.

2 P. Cakir, S. Inan and Y. Altas, Investigation of strontium and uranium sorption onto zirconium-antimony oxide/ polyacrylonitrile (Zr-Sb oxide/PAN) composite using experimental design, J. Hazard. Mater., 2014, 271, 108-119.

3 L. Yuan, Z. Bai, R. Zhao, Y. Liu, Z. Li, S. Chu, L. Zheng, J. Zhang, Y. Zhao, Z. Chai and W. Shi, Introduction of Bifunctional Groups into Mesoporous Silica for Enhancing Uptake of Thorium(Iv) from Aqueous Solution, ACS Appl. Mater. Interfaces, 2014, 6, 4786-4796.

4 R. Akkaya, Removal of radioactive elements from aqueous solutions by adsorption onto polyacrylamide-expanded perlite: equilibrium, kinetic, and thermodynamic study, Desalination, 2013, 321, 3-8.

5 G. R. Choppin and A. Morgenstern, Radionuclide separations in radioactive waste disposal, J. Radioanal. Nucl. Chem., 2000, 243, 45-51.

6 S. Xie, J. Yang, C. Chen, X. Zhang, Q. Wang and C. Zhang, Study on biosorption kinetics and thermodynamics of uranium by Citrobacter freudii, J. Environ. Radioact., 2008, 99, 126-133.

7 D. D. Maksin, A. B. Nastasovic, A. D. Milutinovic-Nikolic, L. T. Surucic, Z. P. Sandic, R. V. Hercigonja and A. E. Onjia, Equilibrium and kinetics study on hexavalent chromium adsorption onto diethylene triamine grafted glycidyl methacrylate based copolymers, J. Hazard. Mater., 2012, 209-210, 99-110.

8 A. Nilchi, T. S. Dehaghan and S. R. Garmarodi, Kinetics, isotherm and thermodynamics for uranium and thorium ions adsorption from aqueous solutions by crystalline tin oxide nanoparticles, Desalination, 2013, 321, 67-71.

9 G. Bayramoglu and M. K. Arica, MCM-41 silica particles grafted with polyacrylonitrile: modification into amidoxime and carboxyl groups for enhanced uranium removal from aqueous medium, Microporous Mesoporous Mater., 2016, 226, 117-124.

10 Y. G. A. El-Reash, A. M. Abdelghany and A. A. Elrazak, Removal and separation of $\mathrm{Cu}(\mathrm{II})$ from aqueous solutions 
using nano-silver chitosan/polyacrylamide membranes, Int. J. Biol. Macromol., 2016, 86, 789-798.

11 E. S. Abdel-Halim and S. S. Al-Deyab, Preparation of poly(acrylic acid)/starch hydrogel and its application for cadmium ion removal from aqueous solutions, React. Funct. Polym., 2014, 75, 1-8.

12 L. Yuan, Y. Liu, W. Shi, Z. Li, J. Lan, Y. Feng, Y. Zhao, Y. Yuan and Z. Chai, A novel mesoporous material for uranium extraction, dihydroimidazole functionalized SBA-15, J. Mater. Chem., 2012, 22, 17019-17026.

13 K. Z. Elwakeel, A. A. Atia and E. Guibal, Fast removal of uranium from aqueous solutions using tetraethylenepentamine modified magnetic chitosan resin, Bioresour. Technol., 2014, 160, 107-114.

14 Z. Bai, L. Yuan, L. Zhu, Z. Liu, S. Chu, L. Zheng, J. Zhang, Z. Chai and W. Shi, Introduction of amino groups into acid-resistant MOFs for enhanced U(vI) sorption, J. Mater. Chem. A, 2015, 3, 525-534.

15 Q. Wang, J. L. Mynar, M. Yoshida, E. Lee, M. Lee, K. Okuro, K. Kinbara and T. Aida, High-water-content mouldable hydrogels by mixing clay and a dendritic molecular binder, Nature, 2010, 463, 339-343.

$16 \mathrm{~N}$. $\mathrm{Wu}$ and $\mathrm{Z}$. $\mathrm{Li}$, Synthesis and characterization of poly(HEA/MALA) hydrogel and its application in removal of heavy metal ions from water, Chem. Eng. J., 2013, 215-216, 894-902.

$17 \mathrm{~J}$. Wang and J. $\mathrm{Li}, \mathrm{Cu}^{2+}$ adsorption onto ion-imprinted composite hydrogels: thermodynamics and mechanism studies, Polym. Bull., 2015, 72, 2143-2155.

$18 \mathrm{H}$. Mittal, A. Maity and S. S. Ray, The Adsorption of $\mathrm{Pb}^{2+}$ and $\mathrm{Cu}^{2+}$ onto Gum Ghatti-Grafted Poly(acrylamide-coacrylonitrile) Biodegradable Hydrogel: Isotherms and Kinetic Models, J. Phys. Chem. B, 2015, 119, 2026-2039.

19 G. Zeng, Y. Liu, L. Tang, G. Yang, Y. Pang, Y. Zhang, Y. Zhou, Z. Li, M. Li, M. Lai, X. He and Y. He, Enhancement of Cd(II) adsorption by polyacrylic acid modified magnetic mesoporous carbon, Chem. Eng. J., 2015, 259, 153-160.

20 Q. Zhu and Z. Li, Hydrogel-supported nanosized hydrous manganese dioxide: synthesis, characterization, and adsorption behavior study for $\mathrm{Pb}^{2+}, \mathrm{Cu}^{2+}, \mathrm{Cd}^{2+}$ and $\mathrm{Ni}^{2+}$ removal from water, Chem. Eng. J., 2015, 281, 69-80.

21 L. Y. Wang and M. J. Wang, Removal of Heavy Metal Ions by Poly(vinyl alcohol) and Carboxymethyl Cellulose Composite Hydrogels Prepared by a Freeze-Thaw Method, ACS Sustainable Chem. Eng., 2016, 4, 2830-2837.

22 Y. Yang and H. Yang, Preparation of Polyacrylic Acid Type Hydrogel and Its $\mathrm{pH}$ Sensitive Behavior in Alkaline Solution, Chin. J. Mater. Res., 2012, 26, 85-90.

23 M. Wei, J. Liao, N. Liu, D. Zhang, H. Kang, Y. Yang, Y. Yang and J. Jin, Interaction between uranium and humic acid (I): Adsorption behaviors of U(vI) in soil humic acids, Nucl. Sci. Tech., 2007, 18, 287-293.

24 H. Yu, S. Yang, H. Ruan, J. Shen, C. Gao and B. V. Bruggen, Recovery of uranium ions from simulated seawater with palygorskite/amidoxime polyacrylonitrile composite, Appl. Clay Sci., 2015, 111, 67-75.

25 T. Liu, J. Fang, Y. Zhang and Z. Zeng, The Effect of Salt and $\mathrm{pH}$ on the Phase Transition Behaviors of $\mathrm{pH}$ and
Temperature-Responsive $\quad \operatorname{Poly}(\mathrm{N}, \mathrm{N}$-diethylacrylamide-comethylacrylic acid), Macromol. Res., 2008, 16, 670-675.

26 B. L. Rivas, H. A. Maturana, X. Ocampo and M. Peric, Adsorption Behavior of $\mathrm{Cu}^{2+}$ and $\mathrm{UO}_{2}{ }^{2+}$ ions on Crosslinked Poly[2,2-bis(acrylamido)acetic acid], J. Appl. Polym. Sci., 1995, 58, 2201-2205.

27 Z. Y. Yang, R. D. Yang, F. S. Li and K. B. Yu, Crystal structure and antitumor activity of some rare earth metal complexes with Schiff base, Polyhedron, 2000, 19, 2599-2604.

28 L. Wang, L. Yuan, K. Chen, Y. Zhang, Q. Deng, S. Du, Q. Huang, L. Zheng, J. Zhang, Z. Chai, M. Barsoum, X. Wang and W. Shi, Loading Actinides in Multilayered Structures for Nuclear Waste Treatment: The First Case Study of Uranium Capture with Vanadium Carbide MXene, ACS Appl. Mater. Interfaces, 2016, 8, 16396-16403.

29 E. Pepo, J. K. Warchol, T. A. Kurniawan and M. E. T. Sillanpaa, Adsorption of Co(II) and Ni(II) by EDTAand/or DTPA-modified chitosan: Kinetic and equilibrium modeling, Chem. Eng. J., 2010, 161, 73-82.

30 M. Monier, D. M. Ayad, Y. Wei and A. A. Sarhan, Adsorption of $\mathrm{Cu}(\mathrm{II}), \mathrm{Co}(\mathrm{II})$, and $\mathrm{Ni}(\mathrm{II})$ ions by modified magnetic chitosan chelating resin, J. Hazard. Mater., 2010, 177, 962-970.

31 T. Lu, T. Xiang, X. L. Huang, C. Li, W. F. Zhao, Q. Zhang and C. S. Zhao, Post-crosslinking towards stimuli-responsive sodium alginate beads for the removal of dye and heavy metals, Carbohydr. Polym., 2015, 133, 587-595.

$32 \mathrm{H}$. Yong-Mei, C. Man and H. Zhong-Bo, Effective removal of $\mathrm{Cu}$ (II) ions from aqueous solution by amino-functionalized magnetic nanoparticles, J. Hazard. Mater., 2010, 184, 392399.

33 W. H. Cheung, Y. S. Szeto and G. McKay, Intraparticle diffusion processes during acid dye adsorption onto chitosan, Bioresour. Technol., 2007, 98, 2897-2904.

34 J. Febrianto, A. N. Kosasih, J. Sunarso, Y. H. Ju, N. Indraswati and S. Ismadji, Equilibrium and kinetic studies in adsorption of heavy metals using biosorbent: A summary of recent studies, J. Hazard. Mater., 2009, 162, 616-645.

35 Q. Peng, Y. Liu, G. Zeng, W. Xu, C. Yang and J. Zhang, Biosorption of copper(II) by immobilizing Saccharomyces cerevisiae on the surface of chitosan-coated magnetic nanoparticles from aqueous solution, J. Hazard. Mater., 2010, 177, 676-682.

36 Y. Chen and J. Wang, Preparation and characterization of magnetic chitosan nanoparticles and its application for Cu(II) removal, Chem. Eng. J., 2011, 168, 286-292.

37 J. S. Wang, R. Peng, J. Yang, Y. Liu and X. Hu, Preparation of ethylenediamine-modified magnetic chitosan complex for adsorption of uranyl ions, Carbohydr. Polym., 2011, 84, 1169-1175.

38 G. Bayramoglu and M. Y. Arica, MCM-41 silica particles grafted with polyacrylonitrile: Modification in to amidoxime and carboxyl groups for enhanced uranium removal from aqueous medium, Bioresour. Technol., 2016, 226, 117-124.

39 A. Zhang, G. Uchiyama and T. Asakura, pH effect on the uranium adsorption from seawater by a macroporous fibrous polymeric material containing amidoxime 
chelating functional group, React. Funct. Polym., 2005, 63, 143-153.

40 W. He, Y. Chen, W. Zhang, C. Hu, J. Wang and P. Wang, Removal of $\mathrm{UO}_{2}{ }^{2+}$ from aqueous solution using halloysite nanotube- $\mathrm{Fe}_{3} \mathrm{O}_{4}$ composite, Korean J. Chem. Eng., 2016, 33, 170-177.

41 F. Zare, M. Ghaedi, A. Daneshfar, S. Agarwal, I. Tyagi, T. A. Saleh and V. K. Gupta, Efficient removal of radioactive uranium from solvent phase using $\mathrm{AgOH}-$ MWCNTs nanoparticles: Kinetic and thermodynamic study, Chem. Eng. J., 2015, 273, 296-306.
42 Y. Jung, S. Kim, S. J. Park and J. M. Kim, Application of polymer-modified nanoporous silica to adsorbents of uranyl ions, Colloids Surf., A, 2008, 313-314, 162-166.

$43 \mathrm{~L}$. Wu, X. Lin, X. Zhou and X. Luo, Removal of uranium and fluorine from wastewater by double-functional microsphere adsorbent of SA/CMC loaded with calcium and aluminum, Appl. Surf. Sci., 2016, 384, 466-479.

44 X. Wang, G. Zhu and F. Guo, Removal of uranium(vi) ion from aqueous solution by SBA-15, Ann. Nucl. Energy, 2013, 56, 151-157. 